\title{
Bioelectromagnetic Paradigm of Cancer Treatment-Modulated Electro-Hyperthermia (mEHT)
}

\author{
Oliver Szasz \\ Department of Biotechnics, St. Istvan University, Budaörs, Hungary \\ Email: biotech@gek.szie.hu
}

How to cite this paper: Szasz, O. (2019) Bioelectromagnetic Paradigm of Cancer Treatment-Modulated Electro-Hyperthermia (mEHT). Open Journal of Biophysics, 9, 98-109.

https://doi.org/10.4236/ojbiphy.2019.92008

Received: January 28, 2019

Accepted: February 24, 2019

Published: February 27, 2019

Copyright (อ 2019 by author(s) and Scientific Research Publishing Inc. This work is licensed under the Creative Commons Attribution International License (CC BY 4.0).

http://creativecommons.org/licenses/by/4.0/

\section{(c) (i) Open Access}

\begin{abstract}
One of the most frequently applied bioelectromagnetic effects is the deep heating of the living species with EMF energy. Despite its long history, hyperthermia is a rarely applied oncotherapy. The reason is its controversial results and complicated control. One of the solutions is concentrating the electromagnetic energy nanoscopically on the parts of the malignant cells instead of heating up the complete tumor-mass. This approach is a kind of non-uniform energy absorption, providing energy liberation only in the selected regions. The energy-absorption of the malignant cells targets the membranes and creates a situation far from thermal equilibrium. The selection of the malignant cells is based on their decided differences from their healthy counterparts. The distinguishing parameters are the electromagnetic properties of the components of the malignant tissue which are the physiologic differences between the malignant cells and their healthy counterparts. The targets realize nano-range heating, using natural nanoclusters on the cell-membrane without artificially implementing them. This energy absorption generates consequent reactions, like programmed cell-death (apoptosis) continued by immunogenic cell-death involving extended immune reactions. The applied radiofrequency current is amplitude modulated by time-fractal modulation pattern. The accurately matched impedance realizes the self-selective mechanisms which are promoted by stochastic resonances. This complex method is a new kind of hyperthermia, named mEHT. Our objective is to analyze the problems of the selective, non-equilibrium energy absorption, and present a solution by the electromagnetic mechanisms for an effective and controllable hyperthermia in oncology.
\end{abstract}

\section{Keywords}

Electromagnetic Effects, RF-Current, Warburg-Effect, Szent-Gyorgyi-Effect, 
Fractal-Physiology, Oncology, Hyperthermia, Nanoscale Heating, Modulated Electro-Hyperthermia, Nanothermia, mEHT, Apoptosis, Immunogenic Cell-Death

\section{Introduction-Hyperthermia Challenges}

Modern hyperthermia treatments in oncology use electromagnetic effects overheating the living object completely (whole body) or partly (regionally or locally). Oncological hyperthermia is intended to be an ideal combination therapy; it provides synergies with most of the conventional treatment modalities, boosts their efficacy and helps to desensitize the previously non-effective treatments.

The history of hyperthermia in oncology has been hectic and controversial [1]. In consequence, the general professional skepticism blocked its application for a long time. Hyperthermia is a constrain energy-delivery, forcing the homeostatic equilibrium to change. From this point the control of the processes became complicated. The adequate dose and protocol of the method and the reproducibility of the results are a complex task; its thermal status is far from equilibrium.

There are multiple physiologic feedbacks trying to re-establish the lost homeostasis. The main correction factors in the thermal control are the blood-flow and the surface regulation processes, like the sweating, orientation control of the hair in the skin, etc. The local heating immediately activates the physiological controls, first of all, the blood-flow, creating intensive heat-exchange conditions to construct a local out-of-equilibrium situation.

The locally or systemically increased blood-flow tries to compensate the growing temperature and cools down the target volume. The blood-flow drastically modifies the specific absorption rate (SAR), irrespective of how accurately it was focused on the tumor-mass. In consequence, the SAR and the temperature mapping of the targeted volume could be significantly different. Therefore, competition starts between the cell-killing potential of the heat and the cancer-supporting potential of the gained blood-supply by higher temperature of the targeted volume.

The focus of the RF-energy is not an easy task, but not impossible. However, the focus of the energy does not mean the focus of the temperature. The temperature is naturally spread by the convective and conductive heat-flow, derived from the temperature gradient and controlled by the physiologic constrains. Temperature-spread is a natural process, its termination is impossible. The time limit is only the heated volume. This is how the ablation techniques work. Also, the isotherms of the heating can be defined only with the help of the time-factor.

Following the temperature distribution is a safety issue, it is important to block the local burn of the healthy tissue, while allowing the temperature for necrosis in the tumor. The temperature control shows the temperature spreading 
well, as well as the formation of the unwanted and uncontrolled hot-spots [2], [3].

Together with the problems of the temperature measurement in depth of the body to control the target, the technical solutions of the energy delivery are also challenging, due to the fact that the deep-heating needs complicated bioelectromagnetic considerations. The energy has to be delivered in depth without overheating the healthy layers between and has to be focused in depth on the heterogeneous and non-regular form of the tumor. The penetration depth of the biological material has frequency dispersion, quickly shortened by the growing frequency, and so contradicting with the demand of high frequency for precise beaming. The bolus-transmitters have to be constructed and non-absorbing but well transferring of the applied electromagnetic effects and the temperature of the body surface has to be limited under the blistering threshold.

To provide enough energy in depth, it needs power of $>20 \mathrm{~W} / \mathrm{kg}$ [4], which is far over the surface tolerance. Usually intensive cooling of the surface is applied to avoid the blisters on the skin. This method has also various physiological feedbacks. When the cooling is too large, the feedback isolates the skin from the deeper cooling, reducing the blood-flow in the subcutane layer under the cooled area. The extra impedance requests higher voltage to provide the same power in the depth as before, increasing the skin jump of the electric field vector perpendicular to the surface. The increased potential will increase the risk of burn.

Due to the challenges, many prospective clinical trials of conventional hyperthermia are questioned [5]. A recognized specialist of hyperthermia formulated a long time ago [6]: "The mistakes made by the hyperthermia community may serve as lessons, not to be repeated by investigators in other novel fields of cancer treatment."

The modulated electro-hyperthermia (mEHT, trademark: oncothermia) offers a new paradigm with nanoscopic heating having adequate answer to the present complex challenges.

\section{Method-Selection Parameters in Nanoscopic Range}

During conventional hyperthermia applications the macroscopic heating concentrates on the equal (homogeneous) temperature of the entire targeted volume or at least it constructs isothermal (isodose) patterns. The above described physiological feedbacks and the very inhomogeneous malignant target make this aim impossible. mEHT as new paradigm of hyperthermia technology declares the non-equal heating, it does not try to reach any macroscopic "isotherm" actionsas usual goal in ionizing radiation. The isotherms are consequences of the "bad reflex" of the equilibrium effects. Due to its heterogeneity, heating in biosystems are anyway far from equilibrium, when the physiological feedback as well as the normal thermodynamical rules are contracting of the macroscopic equilibrium. The method, mEHTdoes not heat the complete tissue in the targeted volume equally [7]. It concentrates the liberation of the absorbed energy 
on the cellular membranes and on the extracellular electrolytes of malignant cells [8]. The microscopically inhomogeneous heating is far from the thermal equilibrium [9]. MEHT applies cellular approach selectively, heating up the malignant cells individually liberating the incident energy in nanoscopic range at the cell-membrane [10]. The energy-absorbers are the membrane rafts, which are clusters of transmembrane proteins, populating the membrane of malignant cells more densely than of the cells of the healthy counterparts. This method does not need any artificially implemented nanomaterials into the target, it uses natural nanoscopic clusters of membrane rafts [11]. Experimental verification of this method shows the significant inducement of apoptosis by this method on lower average temperatures than the isothermal heating does, [12].

The heating energy is not liberated in a sudden single step but is regulated in multiple small energy-absorption processes. This makes it possible to control the energy-liberation and to avoid the overheating the healthy parts. The accurate selection of malignant cells is a key step in the proper mEHT. There are robust electromagnetic differences between the malignant and healthy cells in vivo. The biological processes and structures of the healthy cells are distinguishably different from the malignant ones. These differences make it possible to accurately select the cancer-cells by their electromagnetic behaviors and actively destroy them without damages on their healthy neighborhood.

The main physiological differences between malignant cells and their healthy counterparts are:

1) Differences in the metabolic rate of the malignant and healthy cells (Warburg effect, [13]), which create higher conductivity of tumor than its neighborhood. The increase of the current density in the tumor could be visualized by the measurements of real processes by radiofrequency current density image (RF-CDI), [14] [15] [16] [17]. The Electric Impedance Tomography (EIT) measures and images the tumor based on the impedance differences [18]. This effect could be applied in prophylactics like mammography [19]. Further increase of the conduction selectivity is the positive feedback by growing temperature, [20]. The measured gain of selectivity is active [21], which means $14 \%$ increase by heating of $36^{\circ} \mathrm{C} \rightarrow 43^{\circ} \mathrm{C}$.

2) Differences in the dielectric constant of the extracellular electrolyte and membrane-bound water of the malignant and healthy cells (Szent-Gyorgyi effect, [22]); which allows the selection of malignant cells by their autonomy caused higher dielectric permittivity. The cell-cell adhesion is decreased by the increasing permittivity, [23], which harmonizes with the autonomic malignant cells (disorder in extracellular matrix [24]) and their decreased membrane potential, [25]. The order-disorder phase-transition indicates two different states of the cells: their autonomy status (called alpha-state) and their connected collective status (beta-state), [26].

3) The above two are combined with delta/beta dispersion (Schwan effect) [27]); to select the transmembrane protein clusters (rafts) of malignant cells. There are 
various forms of frequency dependent energy-absorption mechanisms exist, [28], creating variation of the dielectric properties, [29]. The $\beta$-dispersion [30] (known as interfacial polarization effect) is between $0.1-100 \mathrm{MHz}$, it is characteristically determined by the membrane capacities of the cell and the intracellular organelles, bound-water to membrane etc. Responses in this interval are well-connected to the cell-membrane changes. The bound water to the membrane has the upper frequency part of the $\beta$-dispersion, denoted by $\delta$, [31], and so this part is well-selective for the various cell-membrane states. Selective treatments have to be chosen in range of $\beta$-dispersion, [32]. Especially, the difference between the malignant and healthy tissue is that all the electrolyte and membrane properties differ, [33] [34]. The proper selection uses the dipole relaxation of beta-dispersion connected to the membrane bounded water, [35].

4) Structural differences (pathological pattern recognizing) between the malignant and healthy tissues (fractal physiology effect, [36]). The morphology is an important factor of the cellular organization, [37], and varies by kind of tissues. Cellular structures have coordination constrains preferring special coordination arrangements [38], and form self-organized collectivity [39] [40]. The tendency of proliferation is low in the population having small number of cells [41]. A critical cell density is necessary when starting significant cell division, similarly to the observed self-synchronization of chemical oscillators [42]. Dominantly, a favorable topological position (cyclic symmetry of the coordination number) chooses the actual division [43]; justified experimentally too, [44]. Healthy cells work collectively, their energy-consumption, as well as their life-cycles and the availability of resources are controlled in collective way by the various forms of the self-organizing, [45]. The organization process is governed by special "social" signals [46] commonly regulating and controlling the system. The self-organizing in topology is connected to a fractal-structure, which also appears in the dynamic self-similar stochastic behavior of the system, [47].

The special selection effects described above are accurately applied in mEHT, briefly summarized in Figure 1. However, the dose of energy is crucial for all the selection steps. Applying too much energy realizes the classical hyperthermia, it heats up all components of the target, the treatment loses its selection ability. The popular wisdom is valid: the difference between the medicine and poison is only the applied dose.

\section{Results-Technical Realization of Nano-Heating}

MEHT uses the above selection factors targeting the malignant cells with high efficacy, heating it to high temperature very locally (nanoscopic range) and stimulating the immune reactions against the malignant metastases. While the conventional hyperthermia focuses on and targets a macro region, the nanoheating of $\mathrm{mEHT}$ process, is similar to the ionizing radiation concept, which also acts nanoscopically on the DNA of the cells. Radiotherapy destroys the DNA strands, nanotherapy of mEHT destroys the cell-membrane of the malignant cell 


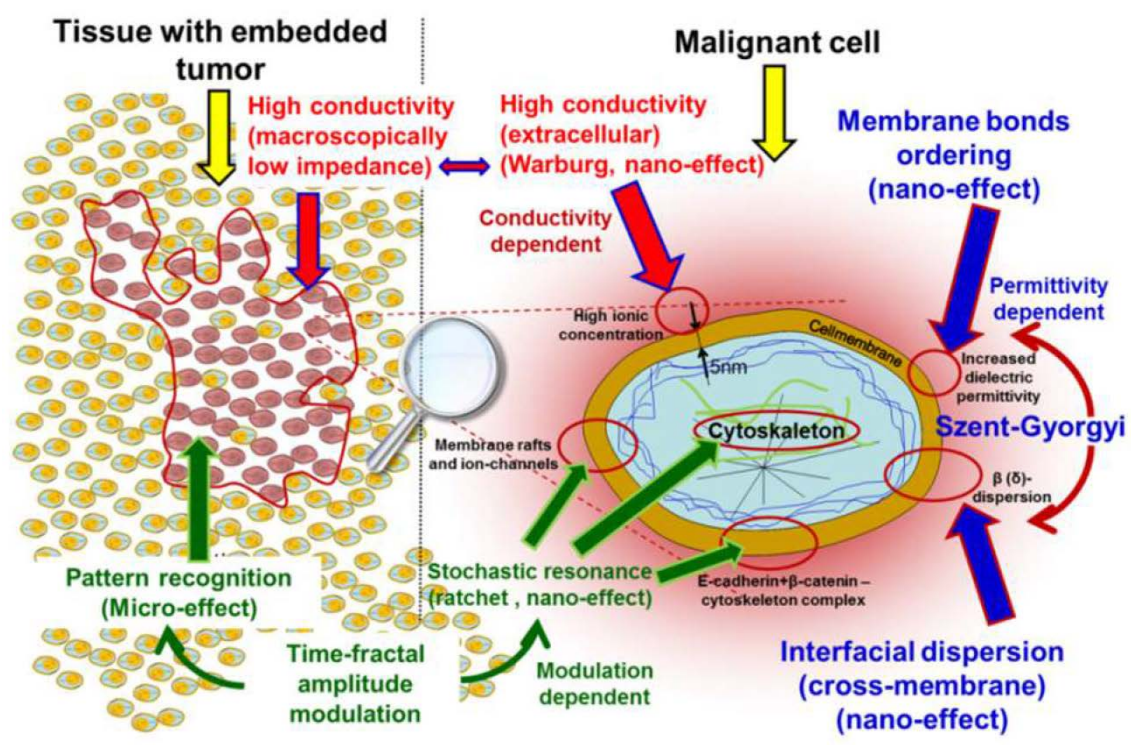

Figure 1. Main selection factors of modulated electrothermia (nanothermia, mEHT) method (to be clear, only those details are shown, which have role in the processes) \{Adapted from $[48]\}$.

or at least induces apoptotic cell death from there, due to the energy-absorption on the clusters of transmembrane proteins, as nanounits.

The electric effects are shown on a schematic impedance figure (Figure 2). The various actions are not independent, effects are overlapping and synergetic.

Heating of the ECM more intensively than the cytoplasm provides a spherical thermal gradient and consequently creates heat-flow through the membrane of all the selected individual cells. This centrally symmetric effect avoids the thermal limit of the external field application [49].

This nanoheating is far from thermal equilibrium. According to the Onsager's reciprocity relations [50], the induced heat-flow is coupled to charge current too, as well as the kinetics of the processes is also coupled, [51]. This current is $~ 150$ $\mathrm{pA} / \mu^{2}{ }^{2}$, [52]. This ionic current creates a zero-mode electric current, which in turn induces a zero-mode electric field in the cell membrane. Therefore, even small fields with zero-th mode components could elicit biological effects.

The temperature gradient through the cellular membrane pumps the non-equilibrium thermal processes. The gradient is quite large $\left(\sim 0.01^{\circ} \mathrm{C} / \mathrm{nm}[\approx\right.$ $\left.\left.107^{\circ} \mathrm{C} / \mathrm{m}\right]\right)$, [46], creating a considerable heat-flow $\left(\sim 1.5 \mathrm{pW} / \mu \mathrm{m}^{2}\right)$. One of the actions is the change of the intracellular pressure (1320 kPa; [46]); by the electro-osmotic conditions. Due to the rigid cell membrane of the cancerous cells [53], the pressure could be fatal for the cell which has maximal tolerable lateral tensile stress of $o \max \approx(2-10) 105 \mathrm{~Pa}$ [54]. The high pressure (when it is not enough to explode the cell) increases the membrane permeability, allowing the internal HSP chaperones to be expressed on the outer membrane to ignite immune reactions. This process is promoted by the temperature effect on the membrane permeability. 


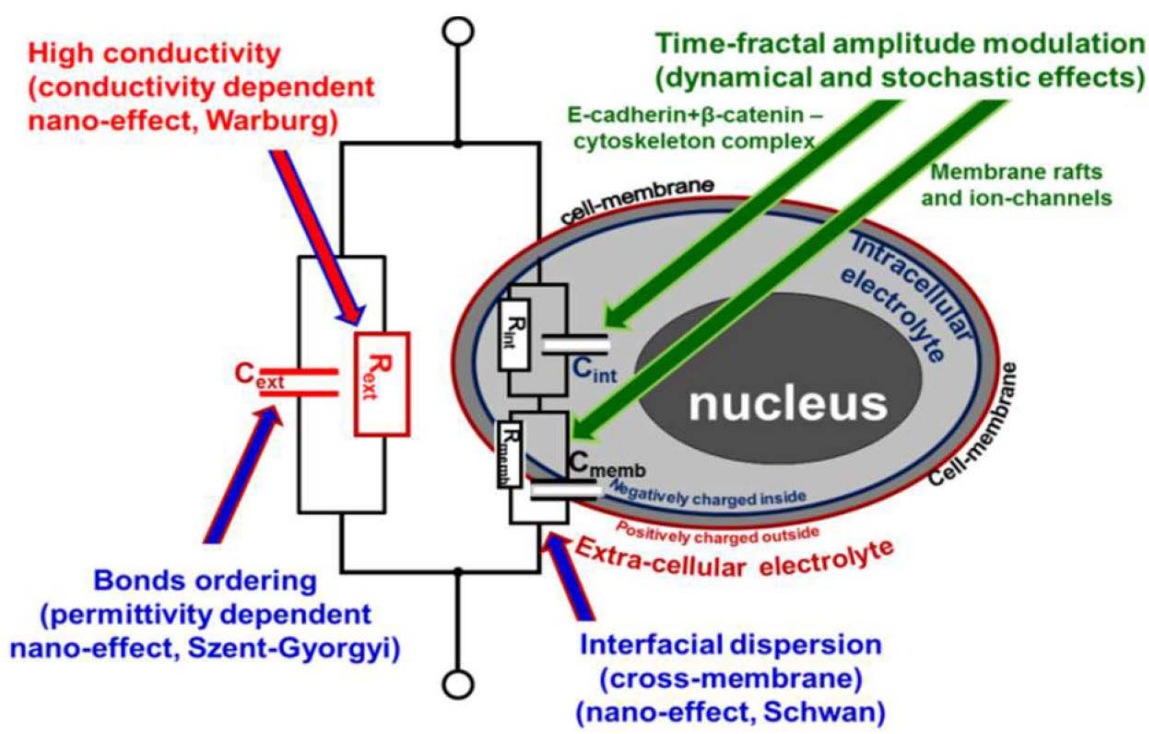

Figure 2. Action of the various selection factors in nanothermia shown in the impedance schematics of a malignant cell \{Adapted from [48]\}.

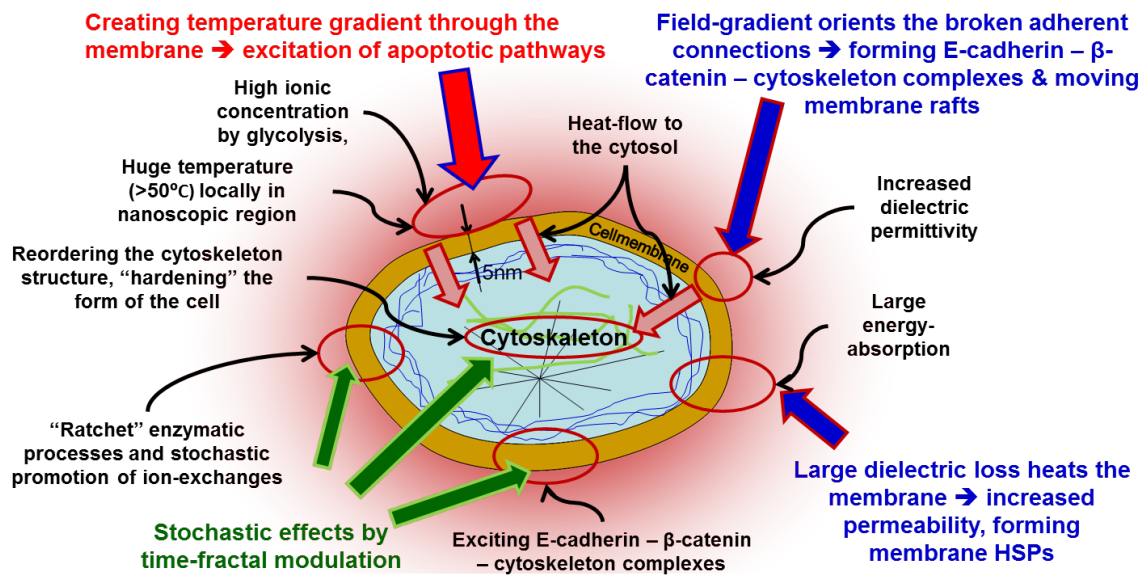

Figure 3. Summary of mEHT selection effects on malignant cell \{Adapted from [48]\}.

The RF-current anyway has special effects characteristically acting on the membrane of the cells. Its ohmic component directly affects the membrane, while the displacement current (imaginary component) deflects it, causing various mechanical effects on the outer membrane. The effect of the ohmic component is proportional with the square of the RF-current (Joule heat) while the capacitive component simply depends on the current itself. The summary of the effects is shown on Figure 3.

The synergy of electric field with the thermal effects selectively acts on the malignant cells and could be well followed from laboratory to the patient's bed, [55]. The certain differences between the mEHT and other hyperthermia with the same temperature are clearly shown by in vitro [56] and in vivo [57] measurements. The immune-simulative effect of the method is also proven [58]. The method has wide and successful clinical applications in various cancer types, like gliomas [59], colorectal cancers, [60] [61]; lung cancers [62] [63], in carcinoma 
of uterine cervix [64], malignant ascites [65], sarcomas [66] [67], pancreas carcinoma [68] [69]; prostate cancer [70] [71].

\section{Conclusion}

Bioelectric explanation of heterogeneric heating of mEHT method is discussed. The method uses nanoheating technology to select and effectively heat the rafts of transmembrane proteins on the membrane of the malignant cells. The bioelectromagnetic selection focuses the electromagnetic absorption on the cell-membranes. The nano-range energy-liberation could be precisely controlled without considerable wasted energy and without having disadvantages because of the heating of the tumor-environment on average. MEHT results and its general benefits open a new kind of local heating to destroy the primary and metastatic tumor lesions.

\section{Acknowledgements}

This work was supported by the Hungarian Competitiveness and Excellence Programme grant (NVKP_16-1-2016-0042).

\section{Conflicts of Interest}

The author declares no conflicts of interest regarding the publication of this paper.

\section{References}

[1] Roussakow, S. (2013) The History of Hyperthermia Rise and Decline. Conference Papers in Medicine, 2013, Article ID 428027.

[2] Gellermann, J., Wlodarczyk, W., Hildebrandt, B., Ganter, H., Nicolau, A., Rau, B., Tilly, W., Fähling, H., Nadobny, J., Felix, R. and Wust, P. (2005) Noninvasive Magnetic Resonance Thermography of Recurrent Rectal Carcinoma in a 1.5 Tesla Hybrid System. Cancer Research, 65, 5872-5880. https://doi.org/10.1158/0008-5472.CAN-04-3952

[3] Wust, P., Hildebrandt, B., Sreenivasa, G., Rau, B., Gellermann, J., Riess, H., Felix, R. and Schlag, P.M. (2002) Hyperthermia in Combined Treatment of Cancer. Lancet Oncology, 3, 487-497. https://doi.org/10.1016/S1470-2045(02)00818-5

[4] Wust, P. (2005) Thermoregulation in Humans, Experiences from Thermotherapy. Conference in Stuttgart, Stuttgart, Germany, 21 November 2005.

[5] Roussakow, S. (2013) Critical Analysis of Electromagnetic Hyperthermia Randomized Trials: Dubious Effect and Multiple Biases. Conference Papers in Medicine, 2013, Article ID 412186.

[6] Storm, F.K. (1993) What Happened to Hyperthermia and What Is Its Current Status in Cancer Treatment? Journal of Surgical Oncology, 53, 141-143. https://doi.org/10.1002/jso.2930530302

[7] Szasz, A. (2013) Challenges and Solutions in Oncological Hyperthermia. Thermal Medicine, 29, 1-23. https://doi.org/10.3191/thermalmed.29.1

[8] Szasz, O. and Szasz, A. (2013) Essentials of Oncothermia. Conference Papers in Medicine, 2013, Article No. 159570.

[9] Szasz, A., Vincze, Gy., Szasz O, and Szasz, N. (2003) An Energy Analysis of Extracellular Hyperthermia. Electromagnetic Biology and Medicine, 22, 103-115. 
https://doi.org/10.1081/JBC-120024620

[10] Szasz, O. and Szasz, A. (2014) Oncothermia-Nano-Heating Paradigm. Journal of Cancer Science \& Therapy, 6, 117-121. https://doi.org/10.4172/1948-5956.1000259

[11] Vincze, Gy., Szigeti, Gy., Andocs, G. and Szasz, A. (2015) Nanoheating without Artificial Nanoparticles. Biology and Medicine, 7, 249.

[12] Andocs, G., Rehman, M.U., Zhao, Q.L., Papp, E., Kondo, T. and Szasz, A. (2015) Nanoheating without Artificial Nanoparticles Part II. Experimental Support of the Nanoheating Concept of the Modulated Electro-Hyperthermia Method, Using U937 Cell Suspension Model. Biology and Medicine, 7, 247.

https://doi.org/10.4172/0974-8369.1000247

[13] Warburg, O. (1966) Oxygen, the Creator of Differentiation. Academic Press, New York.

[14] Mikac, U., Demsar, F., Beravs, K. and Sersa, I. (2001) Magnetic Resonance Imaging of Alternating Electric Currents. Magnetic Resonance Imaging, 19, 845-856. https://doi.org/10.1016/S0730-725X(01)00393-9

[15] Joy, M., Scott, G. and Henkelman, M. (1989) In Vivo Detection of Applied Electric Currents by Magnetic Resonance Imaging. Magnetic Resonance Imaging, 7, 49-54. https://doi.org/10.1016/0730-725X(89)90328-7

[16] Seersa, I., Beravs, K., Dodd, N.J., Zhao, S., Miklavcic, D. and Demsar, F. (1997) Electric Current Density Imaging of Mice Tumors. Magnetic Resonance in Medicine, 37, 404-409. https://doi.org/10.1002/mrm.1910370318

[17] Scott, G.C., Joy, M.L.G., Armstrong, R.L. and Henkelman, R.M. (1995) Electromagnetic Considerations for RF Current Density Imaging [MRI Technique]. IEEE Transactions on Medical Imaging, 14, 515-524. https://doi.org/10.1109/42.414617

[18] Babaeizadeh, S. (2007) 3-D Electrical Impedance Tomography for Piecewise Constant Domains with Known Internal Boundaries. IEEE Transactions on Biomedical Engineering, 54, 2-10. https://doi.org/10.1109/TBME.2006.886839

[19] TransCan, T.S. and Transcan, Medical Ltd. (2000)

[20] McRae, DA., Esrick, M.A. and Mueller, S.C. (1997) Non-Invasive, In-Vivo Electrical Impedance of EMT-6 Tumours during Hyperthermia: Correlation with Morphology and Tumour-Growth-Delay. International Journal of Hyperthermia, 13, 1-20. https://doi.org/10.3109/02656739709056426

[21] Esrick, M.A. and McRae, D.A. (1994) The Effect of Hyperthermia-Induced Tissue Conductivity Changes on Electrical Impedance Temperature Mapping. Physics in Medicine and Biology, 39, 133-144. https://doi.org/10.1088/0031-9155/39/1/008

[22] Szentgyorgyi, A. (1968) Bioelectronics: A Study in Cellular Regulations, Defense, and Cancer. Academy Press, New York.

[23] Szentgyorgyi, A. (1980) The Living State and Cancer. Physiological Chemistry and Physics, 12, 99-110.

[24] Lorusso, G. and Rüegg, C. (2008) The Tumor Microenvironment and Its Contribution to Tumor Evolution Toward Metastasis. Histochemistry and Cell Biology, 130, 1091-1103. https://doi.org/10.1007/s00418-008-0530-8

[25] Yang, M. and Brackenbury, W.J. (2013) Membrane Potential and Cancer Progression. Frontiers in Physiology, 4, 185. https://doi.org/10.3389/fphys.2013.00185

[26] Szentgyorgyi, A. (1998) Electronic Biology and Cancer. Marcel Dekkerm, New York. 
[27] Schwan, H.P. (1982) Nonthermal Cellular Effects of Electromagnetic Fields: AC-Field induced Ponderomotoric Forces. British Journal of Cancer, 45, 220-224.

[28] Pething, R. (1979) Interfacial Dielectric Phenomena in Biological Systems in "Dielectric and Electronic Properties of Biological Materials". John Wiley \& Sons Ltd., New York.

[29] Gabriel, C. (2006) Dielectric Properties of Biological Materials. In: Barnes, F.S. and Greenebaum, B., Eds., Handbook of Biological Effects of Electromagnetic Fields, CRC Press, Boca Raton, 52-95.

[30] Cole, K.S. (1968) Membranes, Ions and Impulses. University of California Press, Los Angeles.

[31] Pennock, B.E. and Schwan, H.P. (1969) Further Observations on the Electrical Properties of Hemoglobin-Bound Water. The Journal of Physical Chemistry, 73, 2600-2610. https://doi.org/10.1021/j100842a024

[32] Schwan, H.P. (1963) Determination of Biological Impedances. Physical Techniques in Biological Research, 6, 323-406. https://doi.org/10.1016/B978-1-4831-6743-5.50013-7

[33] Pliquett, F. and Pliquett, U. (1992) Tissue Impedance, Measured by Pulse Deformation. 8 th International Conference on Electrical Bio-Impedance, Kuopio, 28-31 July 1992, 179-181.

[34] Loft, S.M., Conway, J. and Brown, B.H. (1992) Bioimpedance and Cancer Therapy. 8 th International Conference on Electrical Bio-Impedance, Kuopio, 28-31 July 1992, 119-121.

[35] Pethig, R. (1984) Dielectric Properties of Biological Materials: Biophysical and Medical Applications. IEEE Transactions on Electrical Insulation, 19, 453-474. https://doi.org/10.1109/TEI.1984.298769

[36] Bassingthwaighte, J.B., Leibovitch, L.S. and West, B.J. (1994) Fractal Physiology. Oxford University Press, Oxford.

[37] Zsoldos, I., Szendro, P., Watson, L. and Szasz, A. (2001) Topological Correlation in Amorphous Structures. Computational Materials Science, 20, 28-36. https://doi.org/10.1016/S0927-0256(00)00120-8

[38] Vincze, Gy., Zsoldos, I. and Szasz, A. (2004) On the Aboav-Weaire Law. Journal of Geometry and Physics, 51, 1-12. https://doi.org/10.1016/j.geomphys.2003.08.003

[39] Zsoldos, I. and Szasz, A. (1999) Appearance of Collectivity in Two-Dimensional Cellular Structures. Computational Materials Science, 15, 441-448. https://doi.org/10.1016/S0927-0256(99)00031-2

[40] Maryan, M.I., Kikineshi, A.A. and Szasz, A. (2001) Self-Organizing Processes and Dissipative Structure Formation in the Non-Crystalline Materials. Physics of the Solid State, 2, 585-593.

[41] Puck, T.T., Marcus, P.I. and Cieciura, S.J. (1956) Clonal Growth of Mammalian Cells in Vitro. The Journal of Experimental Medicine, 103, 273-283. https://doi.org/10.1084/jem.103.2.273

[42] Taylor, A.F., Tinsley, M.R., Wang, F., Huang, Z. and Showalter, K. (2009) Dynamical Quorum Sensing and Synchronization in Large Populations of Chemical Oscillators. Science, 323, 614-617. https://doi.org/10.1126/science.1166253

[43] Caer, G.L. (1991) Topological Models of Cellular Structures. Journal of Physics A: Mathematical and General, 24, 1307-1317. https://doi.org/10.1088/0305-4470/24/6/022

[44] Puck, T.T. and Marcus, P.I. (1955) A Rapid Method for Viable Cell Titration and 
Clone Production with Hela Cells in Tissue Culture: The Use of X-Irradiated Cells to Supply Conditioning Factors. Proceedings of the National Academy of Sciences of the United States of America, 41, 432-437. https://doi.org/10.1073/pnas.41.7.432

[45] Camazine, S., Deneubourg, J.L., Franks, N.R., Sneyd, J., Theraula, G. and Bonabeau E. (2003) Self-Organization in Biological Systems. Princeton University Press, Princeton.

[46] Raff, M.C. (1992) Social Controls on Cell Survival and Cell Death. Nature, 356, 397-400. https://doi.org/10.1038/356397a0

[47] Goldberger, A.L., Amaral, L.A.N., Hausdorff, J.M., Ivanov, P.Ch., Peng, C.K. and Stanley, H.E. (2002) Fractal Dynamics in Physiology: Alterations with Disease and Aging. Proceedings of the National Academy of Sciences of the United States of America, 99, 2466-2472. https://doi.org/10.1073/pnas.012579499

[48] Szasz, A. (2015) Bioelectromagnetic Paradigm of Cancer Treatment Oncothermia. In: Rosch, P.J., Ed., Bioelectromagnetic and Subtle Energy Medicine, CRC Press, Boca Raton, 323-336.

[49] Vincze, G., Szasz, N. and Szasz, A. (2005) On the Thermal Noise Limit of Cellular Membranes. Bioelectromagnetics, 26, 28-35. https://doi.org/10.1002/bem.20051

[50] Onsager, L. (1931) Reciprocal Relations in Irreversible Processes. I. Physical Review, 37, 405-426. https://doi.org/10.1103/PhysRev.37.405

[51] Yablonsky, G.S., Gorban, A.N., Constales, D., Galvita, V.V. and Marin, G.B. (2011) Reciprocal Relations between Kinetic Curves. Europhysics Letters, 93, 1-6. https://doi.org/10.1209/0295-5075/93/20004

[52] Szasz, A., Vincze, G., Szasz, O. and Szasz, N. (2003) An Energy Analysis of Extracellular Hyperthermia. Electromagnetic Biology and Medicine, 22, 103-115. https://doi.org/10.1081/JBC-120024620

[53] Galeotti, T., Borrello, S., Minotti, G. and Masotti, L. (1986) Membrane Alterations in Cancer Cells: The Role of Oxy Radicals. Annals of the New York Academy of Sciences, 488, 468-480.

[54] Sackmann, L.E. (1995) Handbook of Biological Physics. Elsevier, Amsterdam, 1.

[55] Andocs, G., Szasz, O. and Szasz, A. (2009) Oncothermia Treatment of Cancer: From the Laboratory to Clinic. Electromagnetic Biology and Medicine, 28, 148-165. https://doi.org/10.1080/15368370902724633

[56] Yang, K.L., Huang, C.C., Chi, M.S., Chiang, H.C., Wang, Y.S., Andocs, G., Wang, H.E. and Chi, K.H. (2016) In Vitro Comparison of Conventional Hyperthermia and Modulated Electro-Hyperthermia. Oncotarget, 51, 84082-84092.

[57] Andocs, G., Renner, H., Balogh, L., Fonyad, L., Jakab, C. and Szasz, A. (2009) Strong Synergy of Heat and Modulated Electromagnetic Field in Tumor Cell Killing. Strahlentherapie und Onkologie, 185, 120-126. https://doi.org/10.1007/s00066-009-1903-1

[58] Tsang, Y.W., Huang, C.C., Yang, K.L., Chi, M.S., Chiang, H.C., Wang, Y.S., Andocs, G., Szasz, A., Li, W.T. and Chi, K.H. (2015) Improving Immunological Tumor Microenvironment Using Electro-Hyperthermia Followed by Dendritic Cell Immunotherapy. BMC Cancer, 15, 708. https://doi.org/10.1186/s12885-015-1690-2

[59] Roussakow, S. (2017) Clinical and Economic Evaluation of Modulated Electrohyperthermia Concurrent to Dose-Dense Temozolomide 21/28 Days Regimen in the Treatment of Recurrent Glioblastoma: A Retrospective Analysis of a Two-Centre German Cohort Trial with Systematic Comparison and Effect-to-Treatment Analysis. BMJ Open, 7, 1-34. 
[60] Hager, E.D., Dziambor, H., Höhmann, D., Gallenbeck, D., Stephan, M. and Popa, C. (1999) Deep Hyperthermia with Radiofrequencies in Patients with Liver Metastases from Colorectal Cancer. Anticancer Research, 19, 3403-3408.

[61] Gadaleta-Caldarola, G., Infusino, S., Galise, I., Ranieri, G., Vinciarelly, G., Fazio, V., Divella, R., Daniele, A., Filippelli, G. and Gadaleta, C.D. (2014) Sorafenib and Locoregional Deep Electro-Hyperthermia in Advanced Hepatocellular Carcinoma: A Phase II Study. Oncology Letters, 8, 1783-1787.

https://doi.org/10.3892/ol.2014.2376

[62] Szasz, A. (2014) Current Status of Oncothermia Therapy for Lung Cancer. Korean Journal of Thoracic and Cardiovascular Surgery, 47, 77-93. https://doi.org/10.5090/kjtcs.2014.47.2.77

[63] Lee, D.Y., Haam, S.J., Kim, H.T., Lim, J.Y., Kim, E.J. and Kim, N.Y. (2013) Oncothermia with Chemotherapy in the Patients with Small Cell. Lung Cancer, 2013, Article ID 910363.

[64] Lee, S.Y., Lee, N.R., Cho, D.H. and Kim, J.S. (2017) Treatment Outcome Analysis of Chemotherapy Combined with Modulated Electro-Hyperthermia Compared with Chemotherapy Alone for Recurrent Cervical Cancer, Following Irradiation. Oncology Letters, 14, 73-78. https://doi.org/10.3892/ol.2017.6117

[65] Pang, C.L.K., Zhang, X., Wang, Z., Ou, J., Lu, Y., Chen, P., Zhao, C., Wang, X., Zhang, H. and Roussakow, S, (2017) Local Modulated Electro-Hyperthermia in Combination with Traditional Chinese Medicine vs. Intraperitoneal Chemoinfusion for the Treatment of Peritoneal Carcinomatosis with Malignant Ascites: A Phase II Randomized Trial. Molecular and Clinical Oncology, 6, 723-732. https://doi.org/10.3892/mco.2017.1221

[66] Jeung, T.S., Ma, S.Y., Choi, J.H., Yu, J., Lee, S.Y. and Lim, S. (2015) Results of Oncothermia Combined with Operation, Chemotherapy and Radiation Therapy for Primary, Recurrent and Metastatic Sarcoma. Case Reports in Clinical Medicine, 4, Article ID: 56280. https://doi.org/10.4236/crcm.2015.45033

[67] Volovat, C., Volovat, S.R., Scripcaru, V., Miron, L. and Lupascu, C. (2014) The Results of Combination of Ifosfamid and Locoregional Hyperthermia (EHY 2000) in Patients with Advanced Abdominal Soft-Tissue Sarcoma after Relapse of First Line Chemotherapy. Romanian Reports in Physics, 66, 175-181.

[68] Volovat, C., Volovat, S.R., Scripcaru, V. and Miron, L. (2014) Second-Line Chemotherapy with Gemcitabine and Oxaliplatin in Combination with Loco-Regional Hyperthermia (EHY-2000) in Patients with Refrctory Metastatic Pancreatic Cancer-Preliminary Results of a Prospective Trial. Romanian Reports in Physics, 66, 166-174.

[69] Dani, A., Varkonyi, A., Magyar, T. and Szasz, A. (2008) Clinical Study for Advanced Pancreas Cancer Treated by Oncothermia. Forum Hyperthermie, 1, 13-20.

[70] Douwes, F.R. and Lieberman, S. (2002) Radiofrequency Transurethral Hyperthermia and Complete Androgen Blockade: A Nonsurgical Approach to Treating Prostate Cancer. Alternative \& Complementary Therapies, 8, 149-156. https://doi.org/10.1089/107628002760090994

[71] Douwes, F.R. (2001) Transurethral Hyperthermia in Early Stage Prostate Cancer. Focus on Alternative and Complementary Therapies, 6, 77-78. https://doi.org/10.1111/j.2042-7166.2001.tb02809.x 